\title{
The Anatomy Lesson of Professor Moxham
}

\section{Karen Ingham}

If you were to enter a theatre of anatomy, what would you expect to see? A musty old museum perhaps, replete with pickled specimens, deformed skeletons, and faded anatomical atlases? Or you may be anticipating a tour of the architectural splendours of the Vesalian Teatro Anatomico in Padua, where executed

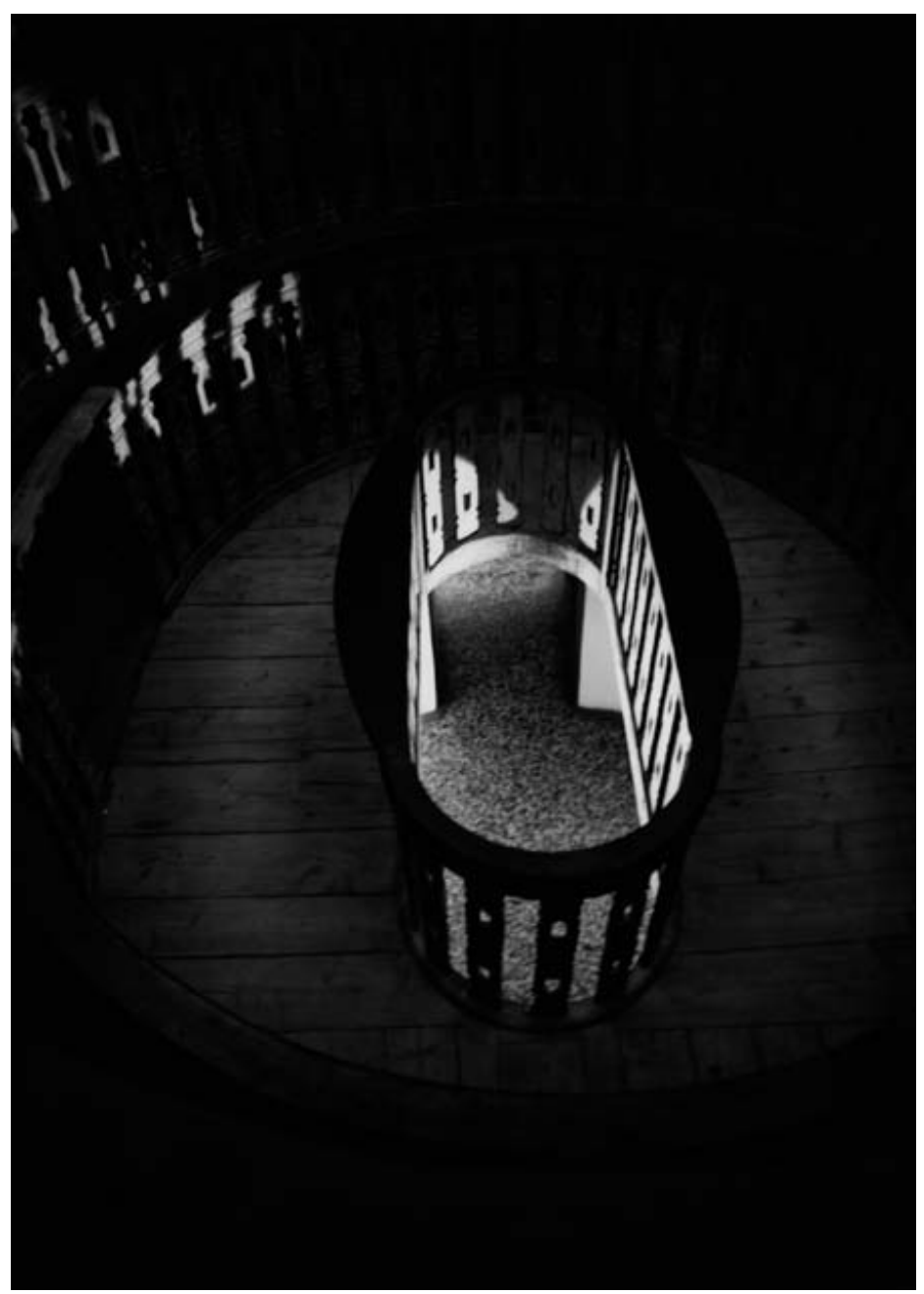

Teatro Anatomico, Padua.

Photo: Karen Ingham.

Reproduced with permission of the photographer. 
criminals had their bodies publicly dissected by the master anatomist for the edification of a paying audience of the great and the good. Perhaps, you expect to glimpse these bodies, their skin pinned back by alphabetical markers like so much loose cloth on a lifeless mannequin? Or are you of the opinion that these spectacles and specimens should remain off-limits to all but staff and students of the medical schools? But what if I were to tell you that from the comfort of your own home, you too may become a spectator in the theatre of the dead, and that the digital body of an executed criminal may be downloaded onto your computer at the flick of a switch, ${ }^{1}$ just as his real body was extinguished when the executioner threw the switch on his 'electric chair'.

Or perhaps you were under the impression that it was only metaphysical mavericks like René Descartes that searched for the soul in the seat of the brain, labouring under the illusion that the 'mind's eye' could, in a fashion, perceive images and sense pain and pleasure through the flow of 'pineal spirits' as he suggested in his complex and ultimately flawed La Dioptrique of $1637 .{ }^{2}$ Descartes's probing fingers were simply too blunt an instrument with which to decode that most complex of organs, the brain, but had he had access to a twenty-first-century fMRI scanner, he would indeed have proved his point that it is possible to 'read' the mind and to render (digitally) what pain and pleasure look like. ${ }^{3}$ It may also surprise you to learn that you may not be so very different from that Vesalian spectator peering over vertiginous Renaissance balconies gawping at the subject made object, only your viewing is restricted to the television screen or computer monitor, or perhaps as a 'ringside' spectator at one of the infamous Gunther von Hagens's 'live' autopsies. ${ }^{4}$ Otherwise, you are no doubt happy to leave the real process of death and degeneration to the experts, placing your trust in high-tech medical scanners that have made the surgeon's eye all but obsolete (see Kember, 1998, p. 55). Ah, but the mastery of the surgeon's hand lives on, you may say. But even this great metaphor of human endeavour and achievement may in time be replaced with nanotechnology that operates from within the diseased and damaged body, leaving the scalpel rusting on the tray while the hand gestures pointlessly.

Meanwhile, the process of death and dying goes on, and palliative carers and undertakers are thriving, and should you elect to be one of the few who donate their bodies to science, you will find yourself being taken apart by would-be surgeons whose understanding of human anatomy is not yet wholly defined by computer simulations where dissection is performed not with a scalpel but with a mouse. And beyond digital simulacra that may yet make the body redundant, what then? For as this essay posits, the epistemic positioning of the body in the anatomo-clinical ${ }^{5}$ theatre is not a purely historic project, and even if it is perceived thus, history, like science, is discontinuous, progressively re-inventing its terms of reference. The theatre of anatomy, and the body 
dissected therein, is not moribund and mothballed but is, conversely, dynamic and evolving.

I am proposing that far from being a relic of the past assigned to the realms of museology, the anatomy theatre is flourishing under new surgical and digital façades. As will become apparent, I am also suggesting that contemporary collaborations between art and bioscience are re-appropriating and re-vitalizing the anatomical theatre, and the collaborative anatomical artworks of the Renaissance and the Baroque, stimulating new discourses on the nature of subjectivity and vision in an era of rapidly changing digital medical technology and genetic transformation. It will be evident in the artworks I discuss that lens-based imaging, and photography in particular, are vital components of this field of creative and scientific endeavour, as the phenomenological authority of the photograph is deeply embedded in our understanding of the anatomoclinical body and its spaces. ${ }^{6}$ My arguments are based in part on the observations and insights I have acquired from working as a cultural producer in what is commonly referred to as 'sciart' collaboration (creative and intellectual partnerships between the arts and sciences). My research is also influenced by arguments for the interdependence of theory and practice and by my interest in the role of the artist as simultaneous cultural and textual producer.

In my practice-based research I have collaborated with anatomists, surgeons and bio-scientists. Correspondingly, the spaces I am excavating, namely the anatomical theatre and its evolution to operating theatre and subsequently to the high-tech laboratories of the digital body, reference the history of these spaces and how these architectures of power influenced the performance of the anatomo-clinical body. Although I refer to the anatomical artworks of the Renaissance and the Baroque, I do not wish to dwell on the history of anatomical representation in these periods, but rather explore how and why the anatomical art produced at that time (which engendered some of the most enduring and inventive visual representations of the human body) continues to exert such a powerful fascination for contemporary artists questioning bodily representation and subjectivity.

I suggest that the hybridity and polysemicism of Renaissance and Baroque anatomo-art collaboration are illustrative of a time when anatomy, art, astronomy and even alchemy could happily interconnect rather than remain the discrete disciplines they are today. This trans-disciplinarity has a particular resonance with contemporary artists who are re-invigorating notions of the Baroque, not as a specific chronological period, but as a scopic regime that encompasses what Christine Buci-Glucksmann has suggestively called 'the madness of vision', a vision which leans towards more open and allegorical expressions of meaning (Buci-Glucksmann, 1986, 1994). The notion of allegory is becoming more prevalent in contemporary arts practice where allegory is perceived 
as constituting something 'other than itself $(\ldots)$ one text read through another' (Berger et al., 1989). Particularly in photographic practice, an allegorical intent in the production of visual meaning is becoming increasingly attractive in a society saturated with visual imagery, a society that is no longer persuaded by photography's guarantee of unproblematic mimetic realities.

The anatomical theatre, historical and contemporary, is a space suffused with allegory, from the Vesalian image of the Fabrica with the dissected female cadaver whose womb comes to represent the Copernican universe - the 'matrix' or womb of meaning ${ }^{7}$ - to the sterile high-tech labs of the Human Genome Project where digital DNA fragments hang suspended in an electronic matrix. The architecture and metaphysics of the anatomical theatre influenced and continue to influence the way the anatomo-clinical body is located within particular hierarchies of power and surveillance, and we know this, in part, through anatomical collaborations that have produced artworks which provoke, stimulate and question the very notion of what it is to be human; images which seek to tell a story and teach a lesson.

\section{The Anatomy Lesson}

Rembrandt's The Anatomy Lesson of Dr Nicolaes Tulp (1632), suggestive as it is of the great suite of Dutch anatomy lesson paintings, is a crucial image in terms of understanding the epistemic structures and scopic regimes of the anatomical body and its theatre. The reading and interpretation of Rembrandt's image is discussed in detail in the work of Jonathan Sawday (1995) and Francis Barker (1995), both of whom bring the theatre of anatomy and its representation well and truly to light in their eloquent and incisive analysis of the Renaissance and Enlightenment cadaver and its entourage. ${ }^{8}$ The performativity of the dead body and the hierarchy of 'players' surrounding the publicly displayed corpse was enacted on the dissecting slabs of leading European theatres of anatomy, where the opening of the body by 'star' anatomists was publicly performed as an allegory of supremacy and revelation.

Having exhibited in the very building in which Rembrandt's painting was hung (Amsterdam's Waag), the painting holds a particular significance and is central to my practice. ${ }^{9}$ The sign in Rembrandt's painting that is perhaps most visible (and the subject of much academic discussion) is that of Tulp's gesturing hand demonstrating the physiological mechanism of the corpse's hand. The hand is a central metaphor for anatomical progress and understanding, and is a particularly visible component of the Baroque suite of anatomy lesson paintings. ${ }^{10}$ Martin Kemp and Marina Wallace note that: 'For artists the hand was a communicative device second only in eloquence to the face. The refined mo- 
tions of Tulp's own left hand precisely demonstrate the subtlety of this intricate piece of bodily design' (Kemp and Wallace, 2000, p. 28). But the real complexity of the hands within the painting becomes apparent in Barker's analysis where he observes that although Tulp's forceps seem to be the ideal instrument with which to epistemically process and reconstitute the criminal body of Aris Kindt $^{11}$ (and I use the term criminal here in its historic not judicial sense as Kindt was little more than a petty thief hardly deserving of execution), they are in fact gesturing towards a fictitious and anomalous anatomy 'lesson'. Not only would an anatomist never begin the process of anatomy with the hand, being compelled by necessity in the days of pre-refrigeration and chemical embalming to open the abdomen and extract and dispose of the already putrefying viscera first, but, according to Barker's contentious argument, the tendons in the palm of Kindt's left hand belong in fact to the back of the right hand (Barker, 1995, p. 71). But the technical minutiae of the hand argument is misleading, for what is at stake here is not realism but symbolism; the painting is not a 'lesson' but an allegorical story of its time. As an allegory the painting can be read on many different levels, its layers of meaning peeled back like loose skin. But herein lies the problem, for where an artist or cultural theorist will eschew absolutism and pedantry, likely components of an actual anatomy lesson, for the anatomist the staging of the body in the anatomical theatre represents a journey from superstition to science, and any detour from realism to relativism is a perilous one. That is why the comparatively recent rapprochement between artists and anatomists is so important in re-establishing what was once a thriving and inventive collaborative partnership. As an example of this process, I want to look at a contemporary photographic tableau that directly corresponds to Rembrandt's Tulp, and to analyse this and several other contemporary artworks within a broader framework of medical-arts collaboration in the anatomical theatre. The Anatomy Lesson of Professor Bernard Moxham is an example from my own sciart practice of a contemporary photographic tableau that re-appropriates Rembrandt's iconic Tulp painting, right down to the detail in the flayed hand of the subject, which is also reversed albeit the reversal was made with pixels rather than paint.

Pixels or paint, the point remains the same; the anatomy lesson paintings are not about the portrayal of medical reality even if the aesthetic employed is one of realism, but are far more densely constructed in terms of allegorical intent and dramatic suspension. Shot in the University of Cardiff dissecting rooms, the Professor and his staff (who like Tulp and his colleagues are practising anatomists) pose in painterly fashion by the subject of their dissective practice, a seated male figure whose hand has been skilfully flayed and taken back to its skeletal form. This tableau vivant pays homage to Rembrandt's Tulp, by re-appropriating the visual grammar of the original painting with the exception that 


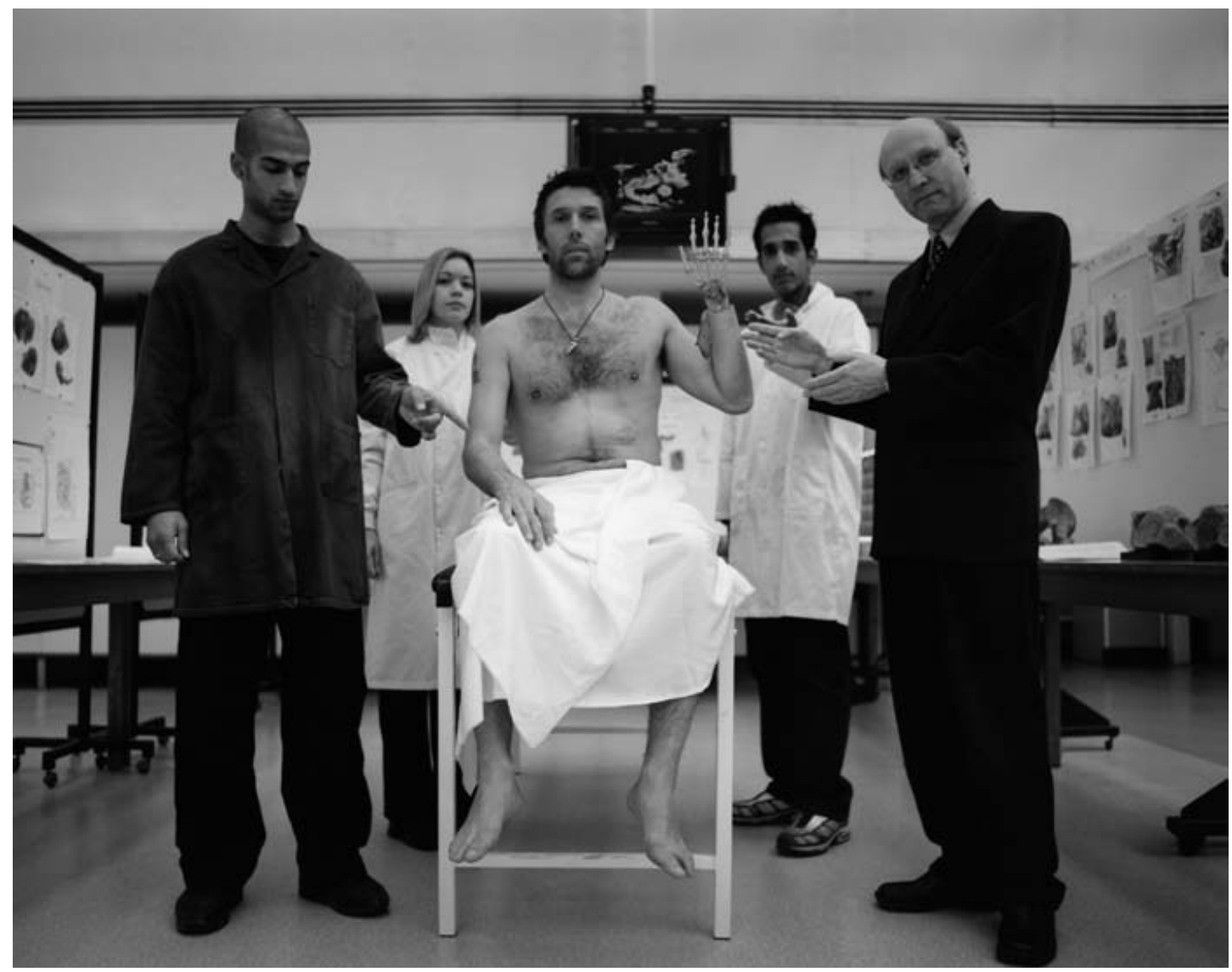

The Anatomy Lesson of Professor Bernard Moxham by Karen Ingham. Reproduced with permission of the artist.

in Moxham's anatomy lesson the instruments of dissection are digital, not surgical. Conversely, on the nearby teaching monitor a 'real' image of re-constructive hand surgery can be seen, implying that in order to successfully re-construct the body, we must acknowledge the anatomist's maxim 'know thyself' by first de-constructing the human form. Where the original anatomy lesson paintings used the medium of their time, paint, I have incorporated contemporary digital technologies, and yet the results are much the same, only now the bodies are donor bodies not those of executed criminals, and a woman is included as an active member of the medical fraternity.

One of the other key objectives of my practice-based research was the public exhibition of the artworks back in their site of origin, the actual dissecting room or anatomy museum, thus enabling the public to experience first hand the drama and latent theatricality of these normally exclusive domains (see Ingham, 2004, pp. 9-10). It is a complex and lengthy process to negotiate the staging of anatomical artworks in functioning pathology and anatomy labs due to the strict regulations regarding health and safety, confidentiality, and, in Britain at least, the 1832 Anatomy Act which is still on the statute books. The members of 
the public who visited the Anatomy Lessons exhibitions in 2003-5 were greeted by the pungent whiff of formaldehyde and working anatomists acted as their 'gallery guides'.

Yet, even anatomy theatres and labs that are no longer operational can be used to powerful effect as Amsterdam's SMART Project Space demonstrated with its 2007 exhibition Fumus Fugiens ${ }^{12}$ which evoked their building's origins as a pathological anatomy lab. The Waag's Theatrum Anatomicum, though redundant for centuries as a functional anatomy theatre, frequently invites the public into this exceptional space, inscribed with the resonant traces of its bloody past, to witness new performances and artworks that re-position the anatomical body. The Waag's partnerships are evidence of the growing academic interest in the anatomical theatre from performance and theatre studies researchers. ${ }^{13}$ This is a welcome development given the relative paucity of material for a subject that is so crucial not only to our understanding of medical epistemology and subjectivity, but also to our knowledge of how the design and performativity of a space significantly influences the nature of the acts that occur within - a kind of ergonomics of anatomy.

The development of the anatomical theatre had a profound effect not only on the evolution of our modern-day operating theatres, but also on the structures and hierarchies of learning implicit in our educational systems, with present-day universities still following the time-honoured hierarchy of professor, reader, lecturer, demonstrator, and technician, first established in the European anatomical theatres of the sixteenth and seventeenth centuries. The 'etiquette' of the anatomical theatre influenced the hierarchical seating plan and performance of the life drawing class, which was modelled on the elliptical dissecting theatres like Padua and Leiden, as evinced in Francois Salle's painting The Anatomy Lesson at the Ecole des Beaux-Arts, Paris (1888). In the life classes at revered art institutions such as The Royal Academy, the model took the place of the cadaver, and artists were seated closer according to experience and social status.

Following the Second World War, artists began to abandon traditional art forms such as figurative painting and drawing in favour of abstraction and new forms of modern art. When medical imaging technologies such as MRI, CAT scans, and powerful electron scanning microscopy came onto the scene, artists were attracted to this new form of bodily abstraction, and the historical relationship of the artist to the nude and to life drawing transformed into a fascination with 'the body'14, and in particular the medical and postmortem body. Maura Flannery has commented that: 'It is ironic that when twentieth-century artists broke away from realism they grasped at elements of another realism: that of the microscopic level' (Flannery, 1998, p. 201). That the anatomo-clinical theatre is of such interest to artists comes as no surprise when we consider the array of 
imaging technologies that contemporary bioscience has at its disposal, or the rich and layered history of anatomical representation that artists can draw on. How beneficial sciart collaboration is to the scientist is another question altogether, and not one which can be brokered here, but a question I have discussed elsewhere. ${ }^{15}$ But what is not in question is that with an informed and speculative collaboration between bio-anatomical science and art, be it textual, visual or performative, the most profound and evocative results sometimes occur.

\section{Performing Allegories in the Theatre of Anatomy}

The artist Helen Chadwick ${ }^{16}$ engaged eloquently and poignantly with the complexities of death and disease. She frequently used allegory in her work as evinced in her installation Unnatural Selection, the result of Chadwick's residency at the IVF unit at King's College Hospital London. Following the artist's unexpected and sudden death, the installation was exhibited posthumously, emphasizing the memento mori associations of the artwork. A series of gemlike, cibachrome photographs set in clear perspex, Unnatural Selection is highly suggestive of the allegorized womb (think again of the Vesalian womb in Fabrica) integrating actual fertilized human eggs discarded by the IVF unit due to possible flaws, creating the most profound 'still life'. Chadwick used her residency at King's to learn first-hand how to locate and extract the eggs needed for her artworks, and in the process of doing so she pushed the boundaries of the emerging sciart discourse. Andrea Duncan describes the artist's engagement with the process of making the work:

Poignantly, in some of the 'frozen' animation within the formalin, Chadwick caught the sperm still trying to enter the protective outer membranes of the fertilized and dividing egg. From these discarded eggs Chadwick created the series of photo pieces, which include works such as Opal, Moonstrance and Nebula. (Duncan, 2000, pp. 153-4)

The use of irony and allegorical intent was already established in Chadwick's work prior to Unnatural Selection, and her earlier works played visibly with Baroque allusions to death and the body. The sense of staging, metaphor and allegorical intent that is evident in the photographic artworks of artists like Chadwick are self-consciously authored appropriations from art historical modes of representation located in the paintings of the Renaissance and the Baroque, with their staged tableaux of the dead and their mediators.

Video artist Andrew Kotting' ${ }^{17}$ work draws heavily on these tableaux and on the Dutch suite of anatomy lesson paintings which differ significantly from 
other anatomical representations in that they are concerned not so much with the physical act of dissection but with the metaphysical staging of the star anatomists reading the body as text within a heightened dramatic space the anatomy theatre as theatre proper (as Barker and Sawday postulate). The anatomy lesson paintings make full use of the visual grammar and drama of the theatre, from Aert Pietersz's The Anatomy Lesson of Dr. Sebastiaen Egbertsz (1603) in which the body is barely visible, such is the throng of surgeons posturing for posterity, to the surreal Anatomy Lesson of Dr. Frederik Ruysch which depicts Ruysch's young son holding the skeleton of a toddler while his father dissects a stillborn infant still attached to its umbilical cord. In Adriaen Backer's Anatomy Lesson of Dr. Frederik Ruysch (1670), the background resembles a staged backdrop, and the impression created is that of a layered, constructed scenario where the only thing that looks alive is, perversely, the cadaver. It is this staging of the pathological body as an allegorical act of disclosure that is alluded to in Kotting's video work and publication Mapping Perception (2002) made in collaboration with neurophysiologist Dr. Mark Lythgoe.

At the heart of the project is an exploration of altered perception through brain dysfunction, as experienced by Kotting's teenage daughter Eden (also a participant in the project), who was born in 1988 with Joubert Syndrome, a rare genetic disorder that profoundly impairs normal neurological functioning. In one of the production's key scenes, Eden is seen lying in a darkened theatre surrounded by what appear to be Dutch anatomists straight out of the anatomy lessons suite. Beautifully lit and staged, the scene of the male anatomists scrutinizing the inert body of the teenage Eden is a profound reminder of the role medicine played in perpetuating positivist notions of difference in terms of the dichotomy between able and disabled, and how we perceive the disabled and they themselves. But what Kotting's work also reminds us of is the role medicine has played in creating male hierarchies of power and knowledge, reducing the female body to little more than a cipher or fetish, primed for de-coding and display as an allegory of the mastery of male science.

Kotting is one of a number of contemporary artists who are using allegory and metaphor to explore contemporary issues of bodily difference in the anatomo-clinical theatre, the work of Alexa Wright being another notable example. Wright is perhaps best known for her photographic tableaux of limb-impaired subjects in her 1998-9 series ' $I$ '. This profoundly challenging and conceptually and visually layered body of work reflects many important issues: the authenticity of the body; the definition and authoring of otherness, particularly in relation to the female body; the use of new technologies to create empowering virtual realities.

In ' $I$ ' Wright creates seductive photographic images that challenge conventions of normality and acceptance in relation to the disabled body. In all but one 
instance Wright carefully juxtaposes her own face onto the disabled body of the sitter. In one of the most widely published images from the series, Wright's virtual and limb-impaired body is located within a baroque setting that plays on the Venus de Milo beautification of the limbless female torso.

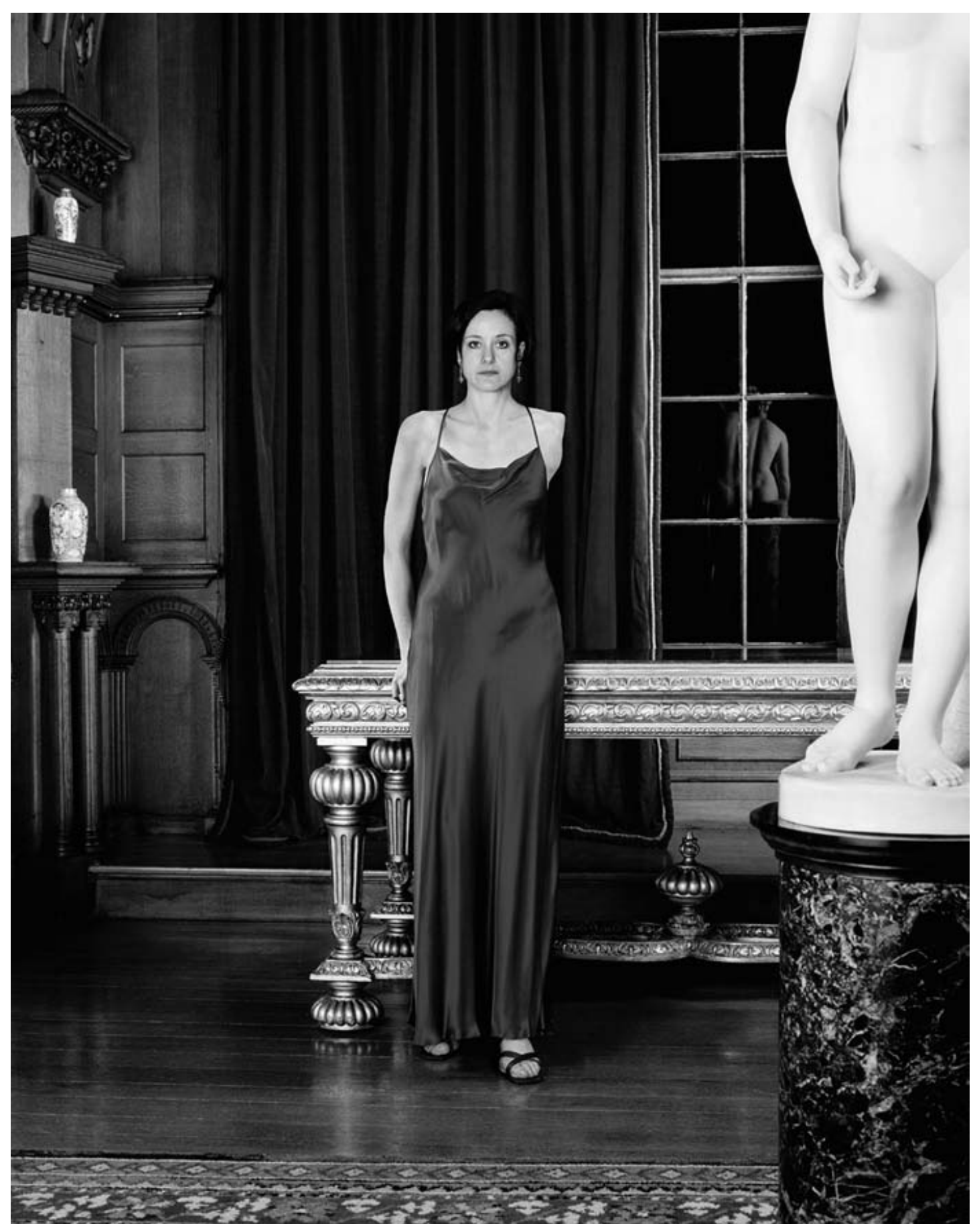

'I' by Alexa Wright. Reproduced with permission of the artist. 
Rachel Gear suggests that:

$[\mathrm{t}]$ he interplay between bodies is particularly important - the head and one arm of the statue remain outside the frame. The reflection in the window hovers between the human figure and the statue to create a shifting sense of wholeness and fragmentation (...) [T] he sitter in this case, Catherine Long, felt able to identify with the image as her own body (...) $[\mathrm{T}]$ he fact that the sitter, on viewing the image, felt that her shoulder belonged to another body is profound. (Gear, 2003, p. 110)

Through negotiation and collaboration, Wright turns what at first glance appears to be a troubling and potentially exploitative situation (Wright herself is not disabled and is thus in a questionable position in representing disability) into an empowering dialogue between able-bodied artist and disabled collaborator, and beyond to the unseen viewer. Collaboration is at the heart of Wright's photographic artworks, and ' $I$ ' was a development from the artist's previous collaborative project After Image (1997), which was informed by dialogue with neuropsychologist Peter Halligan and neurologist John Kew. Working in close collaboration with her limb-impaired subjects, the project helped the amputees come to terms with the phenomena of phantom limb loss. Since 2001 Wright has been a regular collaborator with medical physicist Alf Linney, teaming up to create a number of art and bio-science interactions such as Face Value (2001), Alter Ego (2005) and most recently Conversation Piece (2007).

Wright's working practice is very similar to my own, seeking inventive collaborations through sciart funding agencies, which encourage innovation and engagement with complex biomedical issues. Her work is concerned with questioning notions of normality (and in this sense it could be said to be a visual expression of Georges Canguilhem's 1943 work on the normal and the pathological) and in rupturing society's accepted view of the body.

The artist Neal White also utilizes digital imaging and diagnostic technologies in his work. The first artist in residence at the Human Genome Mapping Project (HGMP) near Cambridge, White's aptly entitled Inheritance (1999) was, like Wright's practice, the result of lengthy collaboration and discussion with his scientific collaborators. The environment at HGMP is sterile and intensely clinical as befits a scientific project using state-of-the-art computer technology to map and analyse complex genetic data, but for an artist, the sterility of such an environment can be visually daunting. White's response to this predicament was to work more conceptually on the notion of genetic identity and inheritance, a task that was made somewhat easier for him through his knowledge of computing and digital technology. In Inheritance 3 White presents us with a pixelated self-portrait that refers to the process of genetic markers. Sian Ede, 
Arts Director of the Calouste Gulbenkian Foundation (the funder of White's residency) describes the image as corresponding:
(...) directly to the number of markers contained within the artist's geno-
type, which was established after a blood sample was refined to pure DNA and marked by HGMP researchers. As a controlling computer causes the pixels to become illuminated one by one, the genotype is gradually revea- led, made human as a photo-image of the artist's face. (Ede, 2000, p. 27)

But I suggest this pixelated 'genetic' face is less an expression of inheritance and individuality (for indeed, its very lack of definition renders it a generalization) than an allegory of anatomy. In its most basic form human anatomy is the systemic analysis of the form, structure, and most especially the internal structure of the body. The aim of the anatomist, put simply, is to deconstruct and disassemble the body in order that we may know it better. However, there are obvious dangers in deconstructing something to the point of erasure, as is possible in the context of digital bodies ${ }^{18}$ or in looking so closely at the interior mechanics of a body that it ceases to exist as a holistic subject, as is the case in the Cartesian machine-body scenario. If you look too closely at Neal White's Inheritance 3, you will see only fragments, chaotic and seemingly random. But step back to view the picture as a whole, and the pixels acquire new form and meaning, and the smiling and reassuring face of the artist comes into focus. Looking closer does not necessarily guarantee greater truth and clarity (although the scientist would argue looking closer does precisely that), and truth is a precarious illusion, as Plato eloquently demonstrated with his oftappropriated metaphor of the darkened cave with the flickering firelight casting shadowy spectres on the wall. ${ }^{19}$

In our digital age, Plato's cave is a valid metaphor for the theatre of the simulacrum. That the body can now be anatomized 'live' and 'performing' (again the reference to 'staging' the body in the theatre of anatomy) through the processes of non-invasive medical imaging technologies implies that we have reached a stage where we no longer require the practice of dissection in the search for medical knowledge. And yet it was the very knowledge that accrued from the act of dissection, and the subsequent advances in medicine, that contributed to the development of Western medicine (and indeed, many aspects of Western philosophy and Western art) as we know it today. But as the interest in 'virtual body' projects suggests, in our celebrity-saturated, youth- and perfection-obsessed society, we have become a culture where death is eschewed, and the 'real' is disavowed in favour of its representation. Bojana Kunst argues in Impossible Becomes Possible that we have already reached the stage where the anatomical has become obsolete: 
If the theory is tenable and the relation between the ideal and real body has been the determining factor in the aesthetic representation of the body, then, at the end of the second millennium, we actually seem to be confronted with none other than 'impossible' bodies - evasive artificial structures, with their 'real' bodies becoming unnecessary and obsolete. (Kunst, 1999, p. 49)

Kunst's words are premonitory, since impossible bodies and the digital technology that produces and reproduces them (from the anatomical theatre to the digital camera) can only exist as fragments of dissected particle, returning us to the notion of a body without organs, a virtual palimpsest, continually erased and inscribed anew through the act of dissection and decoding. In this regard, Kunst reinforces Maaike Bleeker's argument that virtual cadaver projects such as the Visible Human Project are simply more technologically advanced Enlightenment metaphors of the Cartesian machine-body. Bleeker suggests that:

Deploying a rhetoric which evokes memories of a historical understanding of photography, the representatives of the Visible Human Project claim that 'their' bodies are beyond representation. Stressing the continuity between the physical body and the electronic images, they claim that these computer simulations are direct and complete mechanical inscriptions of real human bodies without the gaps or lacks that characterize other representational techniques, and without the distortions that result from human subjective intervention. (Bleeker, 1999, p.5)

The notion of digital technology being closer to 'reality' than traditional means of representation and rendering will be familiar to historians and theorists of photography, where debates about the veracity of the digital medium have been comprehensively rehearsed. But I am positing that virtual 'realities' no more guarantee truth, objectivity, and control than do non-digital means of investigation and representation. Despite the 'virtual' anxiety that digital technology seems to induce, I would argue that even the most extravagant forms of technological and genetic exploration are not yet sophisticated enough to compete with, let alone supersede, the complexity and individuality of an organ as intricate and exquisite as the human brain, which can now be 'seen' to perform within its own theatre of flesh and bone. As theatres of anatomy are mothballed as sites of museology or destroyed in order to make room for more computer workstations, it may seem that the theatre of anatomy is less about the drama of life and death than the downloading of digital bytes of frozen cadavers that only exist as particles of light or pixels of digital encoding. But as the sciart practice of artists like Alexa Wright and Neal White demonstrates, the theatre of the body is still a space suffused with excitement and anticipation, a space 
where power and knowledge continue to be brokered and negotiated, and a space where art and bioscience may find a creative dialogue that furthers our understanding of what it is to be human.

Dr. Karen Ingham is Head of the Centre for Lens-Based Arts (theory \& practice) at the Dynevor Centre for Art, Design and Media at Swansea Institute, Wales, UK. She is a practising artist and writer on the anatomical theatre and the Vanitas memento mori. Her research focuses on creative and provocative dialogues between art, bioscience, philosophy and technology. Her publications include Death's Witness (2000), Anatomy Lessons (2004), Seeds of Memory: art, neuroscience and botany (2006) and the essays 'A Dark Adapted Eye: Photography and the Vanitas Still Life' in Stilled (2006) and 'Palimpsest' in Fumus Fugiens (2007).

\section{Notes}

1 Downloading the digital body at 'the flick of a switch' refers to the 1994 US National Library of Medicine (NLM) initiative the Visible Human Project, an electronic, biological imaging archive which enables the viewer to navigate, in intricate detail, the entire human body in $3 \mathrm{D}$. The aims and objectives of the NLM's project were to create a complete visual archive of the male and female human body that could be readily accessed and downloaded via the Internet for reference in medical and bio-scientific research. The project used the latest medical imaging technology to produce longitudinal scans of a freshly deceased corpse, with the codename of Adam, via magnetic resonance imaging (MRI) and computer tomography (CT). The corpse was then deep frozen to minus seventy degrees centigrade, and rescanned before being cut into quarters (reminiscent of the historical punishment meted out to prisoners in Roman and medieval times who were frequently hung and 'quartered'), and put through an industrial planer before scanning each 'slice'. The reference to the 'quartering' of prisoners is more than incidental, as the real life body behind the code name Adam was indeed a criminal, a death-row inmate by the name of J.P. Jernigan. Jernigan was a murderer, executed in Texas in 1993 after first agreeing to donate his body to NLM's the Visible Human Project. (The precise means of Jernigan's execution was in fact via lethal injection rather than the literal switch of the electric chair.) For more on the Visible Human Project, see Sarah Kember (1998), Maaike Bleeker (1999) and José van Dijck's contribution to this volume (pp. 29-47).

2 In his translation of Descartes's writing, John Cottingham suggests that Descartes was not literally suggesting that the mind could see 'as if there were yet other eyes within our brain', but that the brain, as being ordained by God as the seat of the soul, was somehow able to inspect or 'institute' the images the eye receives independently. See John Cottingham et al. (1985). Descartes's notion of 'the mind's eye' led to what became known as the 'Cartesian Theatre', a term allegedly coined by the philosopher Daniel Dennett (1991). Gen Doy has also written fluently on the subject of the Cartesian Theatre. See Gen Doy (2005). 
Contemporary neurologists and neuropsychologists use functional magnetic resonance imaging (fMRI) to 'see' deep within the cerebral cortex, creating biological images which appear to show sensations of pain and pleasure and even memory itself in the process of forming and consolidating. See Karen Ingham et al. (2006).

Described by the media as Britain's first public autopsy for 170 years, Gunther von Hagens's 'event anatomy', as he describes it, at the Atlantis Gallery in London in 2002 was, I would argue, more of a carnival sideshow than serious public engagement with science. See also Ian Maxwell's contribution to this volume (pp. 49-66). Throughout this essay I refer to the body in the theatre of anatomy as the 'anatomoclinical' body, a phrase used by Michel Foucault throughout his seminal The Birth of the Clinic (1963). I extend the phrase to the actual anatomical theatre itself, the anatomo-clinical theatre, as the theatre of anatomy has many forms and guises, historical, clinical and allegorical.

For more on the phenomenological authority of photography in the representation of the clinical and postmortem body, see Chris Townsend (1998). The theory of the womb as the matrix of knowledge can be read in chapter seven of Jonathan Sawday (1995).

Francis Barker explores the relationship of the theatre of anatomy to the seventeenthcentury-theatre of tragedy in his immensely engaging The Tremulous Private Body: Essays on Subjection (1995). Also see Sawday (1995, p. 45) where he discusses the play The Anatomist within the dissective culture of the period. The multimedia still-life installation and webstream Vanitas was staged at the Waag Theatrum Anatomicum in April 2005 as part of my artist's residency with the Waag. The installation referenced the Waag's history of death and execution, a history which I posited was inscribed in the very fabric of the building. For more on the agency of the hand, see pp. 57-65 in William Schupbach (1982). The history of the judicio-anatomical body and the body's evolution from executed cadaver to an epistemic 'body of knowledge' can be found in Sawday's and Barker's work, and in Ruth Richardson (2001). Barker's work explores in detail the identity and 'crime' of Aris Kindt.

Fumus Fugiens was a group exhibition in Amsterdam's SMART Project Space, a production space for contemporary art. The exhibition was a site-specific response to the building's former function as a pathological anatomical laboratory built in the 1930 .

13 The international Theatres of Science conference at the University of Glamorgan in the UK (2004) attracted a wide variety of papers, many of which were from disciplines like theatre and drama studies, and the international conference The Anatomical Theatre Revisited at the University of Amsterdam (2006) focused on the anatomical theatre, and the anatomical body therein, as a performative space and concept. See also Performance Documentation 5 sensing presence no. 1, pp. 165-168 in this volume.

14 The Artist's Body, by Tracey Warr and Amelia Jones, provides a comprehensive view of how modern and contemporary artists use the body as a site of practice.

15 I discussed this question in my paper 'Descartes Eye: theorizing the art and science of observation' presented at the conference New Constellations: Art, Science and Society at the Museum of Contemporary Art in Sydney (2006). See also Ingham et al. (2006).

16 It was particularly as an installation artist (working at a time when the term installation was itself largely undefined) that the British artist Helen Chadwick (1953-96) came to prominence, working across a range of media and methods of which photography featured prominently. Chadwick's unexpected death, at the age of 42 from heart failure, de- 
prived the art world of a rare visionary. Chadwick influenced a generation of artists, particularly through her work focusing on the body and notions of interiority and sexuality, and for her Baroque staging of those works. Mark Sladen, curator for the 2004 Barbican exhibition Helen Chadwick: A Retrospective, speaks of how the artist set out to defy modern oppositions between mind and body, self and other, stating: 'The Cartesian division between the self and the world is an opposition that Chadwick examines in much of her work' (Sladen, 2004, p. 16). It is this oppositional stance that Chadwick pioneered, working against the assumed binaries of body/mind, female/male, science/art, and that has subsequently led to a culture of collaboration between bioscience and the arts in Britain. Andrew Kotting's film was accompanied by a book and CD-Rom, titled Mapping Perception (2002).

18 In the context of this essay, my definition for a digital body is that used by Harald Begusch in 'Shells that Matter: The Digital Body as Aesthetic/Political Representation' when he states that 'a digital body usually refers to a mathematically computed optical representation which is constructed of grids, pixels and calculated areas and can be associated with the image of a "living' body"' (Begusch, 1999, p. 30 ).

19 The notion of Plato's cave, from Plato's The Republic, has been a recurring motif in discussions on photographic representation and vision, and continues to be cited in relation not only to the history of photographic vision and veracity, but also to the notion of the simulacrum (something that resembles or mimics truth or reality but is in fact a copy).

\section{References}

Barker, F., The Tremulous Private Body: Essays on Subjection. Michigan, 1995. Begusch, H., 'Shells that Matter: The Digital Body as Aesthetic/Political Representation'. In: Performance Research, Vol. 4, No. 2, pp. 30-33. London and New York, 1999.

Berger, John X. et al., Other Than Itself: Writing Photography. Manchester, 1989. Bleeker, M., 'Death, Digitalization and Dys-appearance: Staging the Body of Science'. In: Performance Research, Vol. 4, No. 2, pp. 1-8. London and New York, 1999.

Buci-Glucksmann, C., La folie du voir: de l'esthetique baroque. Paris, 1986.

Buci-Glucksmann, C., Baroque Reason: The Aesthetics of Modernity. London, 1994.

Canguilhem, G., On the Normal and the Pathological. Dordrecht, 1978.

Cottingham, J. et al., The Philosophical Writings of Descartes (Volume I). Cambridge, 1985 .

Dennett, D., Consciousness Explained. New York, 1991.

Doy, G., Picturing the Self: Changing Views of the Subject in Visual Culture. London and New York, 2005.

Duncan, A., 'Inside-Outside - Permutation: Science and The Body in Contemporary Art'. In: Strange and Charmed: Science and the Contemporary Visual Arts. Ede, S. (ed.). London, 2000. 
Ede, S. (ed.), Strange and Charmed: Science and the Contemporary Visual Arts. London, 2000.

Flannery, M., 'Images of the Cell in Twentieth-Century Art and Science'. In: Leonardo, Vol. 3 1, No. 3, pp. 195-204. 1998.

Foucault, M., The Birth of the Clinic. London, 2003. First edition (1963) Naissance de la Clinique, Paris.

Gear, R., 'Beyond the Frame: Narratives of Otherness'. In: Masquerade: Women's Contemporary Portrait Photography. Newton, K. (ed.). Cardiff, 2003.

Ingham, K., Anatomy Lessons. Manchester, 2004.

Ingham, K. et al., Seeds of Memory: art, neuroscience and botany. Cardiff and Swansea, 2006.

Kember, S., Virtual Anxiety: Photography, New Technologies and Subjectivity. Manchester, 1998.

Kemp, M. and M. Wallace, Spectacular Bodies: The Art and Science of the Human Body from Leonardo to Now. London, 2000.

Kotting, A. et al., Mapping Perception. London, 2002.

Kunst, B., 'Impossible Becomes Possible'. In: Performance Research, Vol. 4, No. 2, pp. 47-52. London and New York, 1999.

Richardson, R., Death, Dissection and the Destitute. Chicago, 2001.

Sawday, J., The Body Emblazoned: Dissection and the Human Body in Renaissance Culture. London and New York, 1995.

Schupbach, W., The Paradox of Rembrandt's 'Anatomy of Dr. Tulp'. London, 1982.

Sladen, M., Helen Chadwick. London, 2004.

Townsend, C., Vile Bodies: Photography and the Crisis of Looking. Munich and New York, 1998.

Warr, T. and A. Jones, The Artist's Body. London, 2000. 